\title{
ENTRE O ATIVISMO E A JUDICIALIZAÇÃO DA POLÍTICA: A DIFÍCIL CONCRETIZAÇÃO DO DIREITO FUNDAMENTAL A UMA DECISÃO JUDICIAL CONSTITUCIONALMENTE ADEQUADA
}

\author{
BETWEEN ACTIVISM AND JUDICIALIZATION OF POLICY: THE DIFFICULT CONCERTATION OF \\ FUNDAMENTAL LAW TO A DECISION CONSTITUALLY JUDICIAL ADEQUATE
}

Lenio Luiz Streck"

Resumo: Em uma democracia estável, o direito ocupa um papel central na organização da engenharia institucional, ao definir as condições mínimas para o funcionamento do sistema político. Ao mesmo tempo, o reconhecimento de novos direitos pelo Constitucionalismo Contemporâneo ocasiona uma atuação mais destacada do Poder Judiciário; essa situação, muitas vezes, é confundida pela comunidade jurídica como uma justificativa para decisões sem qualquer critério de racionalidade, baseadas na mais pura discricionariedade judicial. Torna-se necessário enfrentar os desafios que tem o Poder Judiciário para - no limite, em face da incompetência dos demais Poderes - contribuir para a concretização dos direitos fundamentais. Isso implica, fundamentalmente, enfrentar o tema a partir da necessária diferenciação entre os fenômenos do ativismo judicial e da judicialização da política. Afinal, uma decisão constitucionalmente adequada também deve ser observada como um direito fundamental do cidadão.

Palavras-chave: Ativismo judicial. Judicialização da política. Direitos fundamentais. Decisão judicial constitucionalmente adequada.
Abstract: In a stable democracy, law occupies a central role in the organization of institutional engineering, in defining the minimum conditions for the functioning of the political system. At the same time, the recognition of new rights by the Contemporary Constitutionalism causes a more outstanding performance of the Judiciary Power. This situation is often confused by the legal community as a justification for decisions without any criterion of rationality, based on pure judicial discretion. It is necessary to face the challenges that the Judiciary has to - in the limit, due to the incompetence of the other Powers - to contribute to the realization of fundamental rights. This implies, fundamentally, to face the issue from the necessary differentiation between the phenomena of judicial activism and the judicialization of politics. After all, a constitutionally appropriate decision must also be observed as a fundamental right of the citizen.

Keywords: Judicial activism. Judicialization of politics. Fundamental rights. Judicial decision. 


\section{Introdução}

Refletir sobre a efetivação dos direitos humanos e fundamentais nesta quadra da história é pensar também acerca das condições de possibilidade de sua efetivação (jurídica) em consonância com a democracia e os limites do direito, caso contrário muitas conquistas esconderão, na realidade, outros problemas. Direitos podem ser concedidos ad hoc? Uma decisão ativista (no sentido que está especificado neste artigo) não fere direitos fundamentais de outras pessoas que se encontram nas mesmas condições?

Dito de outro modo, por vezes ouvem-se discursos em prol do reconhecimento e da concretização de direitos pela via judicial que não consideram que a prestação jurisdicional não é ilimitada e que o "jogo" democrático tem de ser respeitado. Senão, partiremos de uma demo-cracia para uma juristo-cracia, o que certamente traria consequências outras tão danosas ou mais graves do que aquelas que intentamos suplantar.

Assim, cada vez mais se torna necessário discutir o papel do direito na democracia, suas possibilidades e sua força normativa. Em outras palavras, na contemporaneidade não pode ser considerado válido um direito que não seja legitimado pelo selo indelével da democracia, inclusive os direitos humanos.

A nova acepção do direito está bem-representada naquilo que Jorge Miranda chamou de "Revolução Copernicana do Direito Público", ou seja, o novo lugar ocupado pelas Constituições do segundo Pós-guerra e pelos Tribunais Constitucionais, mormente no campo da Europa Continental.

Desse modo, é importante lembrar que é nesse contexto de afirmação das Constituições e do papel da jurisdição constitucional que teóricos dos mais variados campos das ciências sociais principalmente dos setores ligados à sociologia, à ciência política e ao direito - começaram a tratar de fenômenos como a judicialização da política e o ativismo judicial. Ambos os temas passam pelo enfrentamento do problema da interpretação do direito e do tipo de argumento que pode, legitimamente, compor uma decisão judicial.

Nessa conjuntura exsurgem questões como: todo e qualquer argumento serve como fundamento de uma decisão jurídica? Sob quais circunstâncias é possível afirmar que o tribunal, em sua interpretação do direito, não está substituindo os demais Poderes da República, Legislativo ou Executivo, proferindo argumentos de política ou de moral, entre outros?

Longe de ser um mero exercício teórico, o modo como respondemos a essas indagações tem repercussões políticas e sociais que, em última instância, podem fortalecer ou fragilizar as pretensões (supostamente) emancipatórias. Destarte, o grande desafio hermenêutico do direito no século XXI é controlar hermeneuticamente as decisões judiciais, especialmente diante do deslocamento da concretização dos direitos previstos na Constituição pelo Judiciário.

Com a Constituição de 1988 tivemos a necessidade de buscar novos modos de análise: no mínimo, uma nova teoria das fontes, uma nova teoria da norma, uma nova teoria interpretativa e, fundamentalmente, uma teoria da decisão (teoria da validade). A pergunta que se coloca(va) é(era): de que modo pode(ría)mos olhar o novo com os olhos do novo? Afinal, nossa tradição jurí- 
dica está(va) assentada em um modelo liberal-individualista (que opera com os conceitos oriundos das experiências da formação do direito privado francês e alemão), em que não havia lugar para direitos de segunda e terceira dimensões, tampouco as discussões hodiernas sobre direitos humanos. Do mesmo modo, não há uma teoria constitucional adequada às demandas de um novo paradigma jurídico.

No intento de desenvolver uma teoria jurídica apropriada a essa nova realidade, temos gestado ao longo das últimas décadas a Crítica Hermenêutica do Direito. ${ }^{1}$ Uma de nossas maiores preocupações é que a decisão jurídica esteja em consonância com as exigências democráticas e constitucionais, donde radica sua legitimidade. Então, a resposta jurídica apresenta-se como uma decisão, que pressupõe responsabilidade política, e não como uma escolha (livre) que deva ser avaliada pelas suas consequências.

Numa democracia estável, o direito ocupa um papel central na organização da engenharia institucional, ao definir as condições mínimas para o funcionamento do sistema político. Ao mesmo tempo, o reconhecimento de novos direitos pelo Constitucionalismo Contemporâneo ocasiona uma atuação mais destacada do Poder Judiciário; essa situação, muitas vezes, é confundida pela comunidade jurídica como uma justificativa para decisões sem qualquer critério de racionalidade, baseadas na mais pura discricionariedade judicial.

Nessa linha, torna-se necessário enfrentar os desafios que tem o Poder Judiciário para - no limite, em face da incompetência dos demais Poderes - contribuir para a concretização dos direitos fundamentais. Isso implica, fundamentalmente, enfrentar o tema a partir da necessária diferenciação entre os fenômenos do ativismo judicial e da judicialização da política. Afinal, uma decisão constitucionalmente adequada também deve ser observada como um direito fundamental do cidadão.

\section{Ativismo versus judicialização}

Em texto publicado recentemente, Vianna (2016) afirma não haver limites na patologia que é a judicialização da política, e que, nesse sentido, o Supremo Tribunal Federal atravessou o Rubicão com a recente judicialização do rito do impeachment. Esse é um assunto que me é caro, pois venho realizando reflexões sobre ele há muito tempo. De pronto, penso que Werneck Vianna mais se refere ao ativismo judicial do que propriamente à judicialização da política. E se sua crítica

\footnotetext{
1 Em síntese, a Crítica Hermenêutica do Direito (CHD) apresenta-se com uma matriz teórica de análise do fenômeno jurídico. Fundamentalmente, move-se nas águas da fenomenologia hermenêutica, pela qual o horizonte do sentido é dado pela compreensão (Heidegger), e ser que pode ser compreendido é linguagem (Gadamer), em que linguagem não é simplesmente objeto, e sim, horizonte aberto e estruturado e a interpretação faz surgir o sentido. Com esses pressupostos, incorporam-se aportes da teoria jurídica de Ronald Dworkin. Isso é explicitado amiúde em obras como Hermenêutica Jurídica e(m) crise, Verdade e Consenso e Jurisdição Constitucional e Decisão Jurídica. A tarefa da Crítica Hermenêutica do Direito (CHD) é a de "desenraizar aquilo que tendencialmente encobrimos" (Heidegger-Stein). Fincada na ontologia fundamental, busca, mediante uma análise fenomenológica, o desvelamento (Unverborgenheit) daquilo que, no comportamento cotidiano, ocultamos de nós mesmos (Heidegger): o exercício da transcendência, no qual não apenas somos, mas percebemos que somos (Dasein) e somos aquilo que nos tornamos por meio da tradição (pré-juízos que abarcam a faticidade e historicidade de nosso ser-nomundo, no interior do qual não se separa o direito da sociedade, isso porque o ser é sempre o ser de um ente, e o ente somente é no seu ser, sendo o direito entendido como a sociedade em movimento), e onde o sentido já vem antecipado (círculo hermenêutico).
} 
se limitar a essa parte específica da "política", penso que fica de fora a maior parte do problema. O problema do ativismo é muito maior do que o da judicialização, isso porque Werneck coloca ativismo e judicialização no mesmo patamar ou não faz diferença entre os dois. Existe diferença entre esses dois fenômenos. O ativismo sempre é ruim para a democracia, porque decorre de comportamentos e visões pessoais de juízes e tribunais, como se fosse possível uma linguagem privada, construída à margem da linguagem pública. Já a judicialização pode ser ruim ou pode não ser. Depende dos níveis e da intensidade em que ela é verificada. Na verdade, sempre existirá algum grau de judicialização (da política) em regimes democráticos que estejam guarnecidos por uma Constituição normativa. Por isso, é possível observá-la em diversos países do mundo. Aliás, ainda recentemente, viu-se isso na Alemanha e nos Estados Unidos. Por vezes, para a preservação dos direitos fundamentais, faz-se necessário que o Judiciário (ou os Tribunais Constitucionais) seja chamado a se pronunciar toda a vez que existir uma violação por parte de um dos Poderes à Constituição. Portanto, a judicialização decorre de (in)competência - por motivo de inconstitucionalidades - de poderes ou instituições. ${ }^{2}$

A questão da judicialização (da política), portanto, está ligada ao funcionamento (in)adequado das instituições, dentro do esquadro institucional traçado pela Constituição. Quanto maior a possibilidade de se discutir, no âmbito judicial, a adequação ou não da ação governamental lato sensu em relação aos ditames constitucionais, maior será o grau de judicialização a ser observado.

É por isso que afirmo, como já o fiz em outras oportunidades, ${ }^{3}$ que a judicialização é contingencial. Ela depende de vários fatores que estão ligados ao funcionamento constitucionalmente adequado das instituições. $\mathrm{O}$ ativismo judicial, por outro lado, liga-se à resposta que o Judiciário oferece à questão objeto de judicialização. No caso específico da judicialização da política, o ativismo representa um tipo de decisão na qual a vontade do julgador substitui o debate político (seja para realizar um pretenso "avanço", seja para manter o status quo). Ativismo é, assim, um behaviorismo judicial.

Assim, de uma questão que sofreu judicialização se pode ter como consequência uma resposta ativista, o que é absolutamente ruim e censurável em uma perspectiva de democracia normativa. Todavia, é possível afirmar que existem casos de judicialização nos quais a resposta oferecida pelo Judiciário é adequada à Constituição, concretizadora de direitos fundamentais e/ou procedimentos guarnecedores da regra democrática e que, portanto, não pode ser epitetada de ativista. Afinal, como diz Oliveira (2015), há situações em que a jurisdição constitucional deve ser agressiva no sentido da garantia dos direitos fundamentais.

Esclarecido isso, apenas agrego que, lendo o texto de Werneck Vianna, tem-se a impressão - ou corre-se o risco de que alguém possa tê-la - de que a judicialização (sempre) é ruim. Nesse pon-

\footnotetext{
2 Essa diferença entre ativismo e judicialização é de fundamental importância. Não me parece que se possa fazer uma crítica adequada se confundirmos os dois conceitos. A menos que tudo seja considerado judicialização, o que diminuiria sobremodo o papel da jurisdição, mormente em países periféricos. Nesse sentido, temos os trabalhos de Vanice do Valle e José Ribas Vieira, além de Clarissa Tassinari. Esse problema do ativismo afeta a democracia, havendo excelentes estudos acerca dessa pauta de autores como Marcelo Cattoni, Gilberto Bercovi, Martonio Barreto Lima, Otavio Luiz Rodrigues Júnior, Rafael Tomaz de Oliveira, Danilo Pereira Lima, Geroges Abboud, André Karam Trindade, Alexandre Morais da Rosa, entre outros.

3 Nesse sentido, ver, principalmente, alguns livros de minha autoria que tratam do assunto: Streck (2015, 2014a, 2014b).
} 
to, embora o Professor tenha uma visão crítica relevante acerca da relação entre os Poderes, a crítica à judicialização - sem distingui-la do ativismo - pode enfraquecer sobremodo a jurisdição constitucional. A menos que venhamos a aderir a uma postura mais radical, da qual Jeremy Waldron é um dos expoentes - no sentido de que questões políticas e morais polêmicas, a respeito das quais haja um desacordo razoável estabelecido na comunidade política, não devam, por princípio, ser resolvidas pelo Poder Judiciário. Não esqueçamos que sempre é tentador elaborar olhares externos ao direito, como é próprio de posturas como o positivismo exclusivo no qual se pode enquadrar Waldron.

Há uma pergunta fundamental que deve ser feita e que pode dar um indicador se a decisão é ativista ou não: a decisão (uma determinada decisão), nos moldes em que foi proferida, pode ser repetida em situações similares? Sendo a resposta um "não", há fortes indícios de que estejamos a ingressar no perigoso terreno do ativismo. Nesse sentido, o acórdão da lavra do Desembargador Alexandre Freitas Câmara, do Tribunal de Justiça do Rio de Janeiro, é uma decisão extremamente importante, pois sustenta a ideia de universalidade dos direitos fundamentais como pressuposto para a compreensão do caso. O juízo de primeiro grau havia concedido uma medida liminar, de acordo com o pedido apresentado pelo Ministério Público, com a finalidade de obrigar a administração pública do Município de Campos dos Goytacazes a incluir a família de uma criança em programa de auxílio à moradia em razão de esta ter sido vítima de abusos sexuais. De acordo com a decisão, "[...] [a administração pública] deveria garantir acesso à moradia da menor, que atualmente vive em condições precárias e de risco, tendo em vista que já foi vítima de abuso sexual e seu abusador reside próximo à sua casa." Apesar dos indicativos apresentados pelo MP de precariedade econômica e social em que a jovem se encontrava e, além disso, tendo supostamente sido vítima de estupro, as questões jurídicas que se colocavam eram as seguintes: haveria um direito fundamental à moradia para vítimas de estupro? Existiria universalidade nesse caso? No agravo de instrumento apresentado pelo Município, o voto do Desembargador Alexandre Freitas Câmara primeiramente demonstrou que não haveria as condições para a concessão da liminar (periculum in mora e fumus boni iuris), para logo depois evidenciar que, diante da falta de universalidade, não haveria um direito fundamental à moradia para vítimas de abusos sexuais. De acordo com ele, "[...] há direito fundamental - este, sim, universalizável - ao ressarcimento do dano; há direito fundamental ao afastamento do agressor. Nada disso, porém, foi pedido pelo Ministério Público. Não há, todavia, direito fundamental a uma nova moradia para vítima de violência." O interessante é que, de acordo com o acórdão, o MP não chegou a se manifestar a respeito do crime de estupro de vulnerável por meio de ação penal contra o agressor, abrindo mão de perseguir o suposto autor do crime para preservar a vítima de novos casos de abuso. Ou seja, diante da ausência de universalidade de um suposto direito fundamental à moradia para vítimas de estupro, é possível afirmar que a posição do MP e do magistrado prolator da decisão agravada não se sustenta juridicamente, e que o voto do Desembargador foi constitucionalmente correto (RIO DE JANEIRO, 2015).

Em um texto recente (STRECK, 2016), escrevi acerca do grau de ativismo existente no País, mormente na Suprema Corte. Dizia, então, que uma decisão é ativista até mesmo quando, por exemplo, concede a metade da herança para a concubina-adulterina, assim como é ativista uma 
decisão que diz que é juízo discricionário dizer se pode haver prova antecipada no caso do artigo 366 do Código de Processo Penal (CPP). Também foi ativista a decisão do STF no caso das uniões homoafetivas (não gostaria de debater o mérito desse assunto, novamente - apenas cito a decisão como amostragem de ativismo, nada mais) (STRECK; OLIVEIRA; PARRETTO, 2009). E sobre terras indígenas. E o caso Donadon no MS 32.326. E o que dizer do Estado de Coisas Inconstitucional (ECI) (STRECK, 2015)? Assim, o direito à saúde pode ser concedido por decisões que concretizam adequadamente o direito, como também por decisões ativistas. Por exemplo, conceder um tratamento que consumirá um terço do orçamento do município é um caso de judicialização que acaba em ativismo. Um exemplo explícito de ativismo: foi ativista a decisão que autorizou o consumo da pílula contra o câncer e que provocou uma corrida ao Judiciário. No mais, decisões contra legem são (também) práticas ativistas, porque, nesse caso, o juiz se assenhora da lei e coloca os seus juízos pessoais no lugar dos do constituinte e/ou do legislador ordinário. Também é ativista decisão que confunde explicitamente os conceitos de texto e norma (STRECK, 2013), remetendo o direito aos cânones formalistas.

Entenda-se bem: nem toda a resposta juridicamente errada é, por ser errada, ativista; aliás, a postura pode ser ativista, e a resposta jurídica, correta. A questão é que, somente pelo fato de ser ativista, há um problema de princípio que a torna errada, na sua formulação. É uma questão de dever judicial.

Igualmente é uma confissão de ativismo quando se diz que o Supremo Tribunal é a vanguarda iluminista do País, porque ele, o Supremo, teria vocação para "empurrar a história". ${ }^{4}$ Decisões no plano da jurisdição constitucional objetiva costumam correr menos risco de ativismo, embora possam, sim, a pretexto de judicialização em face de contingências, ingressar nesse terreno.

Por outro lado, o STF ou outros Tribunais podem declarar a inconstitucionalidade de leis em alto índice e, ainda assim, necessariamente, essa atitude não ser ativista. Se as leis forem inconstitucionais, é bom para a democracia - ou, diria, condição de possibilidade dela - que sejam assim declaradas nulas. Ativismo ou judicialização não se captam a partir do código "constitucional-inconstitucional" e tampouco do código "ação deferida-ação indeferida". Os conceitos de ativismo e judicialização que explicito é que dão o limite do sentido e o sentido do limite da discussão. Se lermos as críticas à judicialização de modo radical como o faz Werneck Vianna, correremos o risco de criticar até mesmo decisões em ações diretas de inconstitucionalidade que nulificam leis as quais ferem a Constituição. De novo: por isso uma coisa é o ativismo, outra é a judicialização.

\section{De como a concretização dos direitos fundamentais não é sinônimo de ativismo judicial}

É nesse caldo de cultura que, no presente artigo, realiza-se uma reflexão sobre esse enorme contingente de decisões cotidianas sobre as quais não há controle e das quais pouco se fica sabendo,

\footnotetext{
4 Em entrevista à Folha de São Paulo, o Ministro Luis Roberto Barroso fez a seguinte afirmação: "[...] a gente, para fazer andar a história, não precisa estar com o povo gritando atrás. É preciso interpretar e fazê-la andar [...] Está ruim, não está funcionando, nós temos que empurrar a história. Está emperrado, nós temos que empurrar." Ou seja, segundo o Ministro do STF, em casos de inércia do Legislativo, cabe ao Judiciário a tarefa de empurrar a história. É como se, na atual conjuntura, os juízes devessem se portar como vanguarda das transformações sociais. O resultado dessa posição nós já conhecemos: mais discricionariedade. Nesse sentido, ver Rodrigues (2013).
} 
a não ser que envolvam assuntos polêmicos com autoridades em geral ou causas com apelo social, aptos a ganhar relevância nas redes sociais. Os próprios textos legais, quando dão azo ao livre convencimento, livre apreciação da prova, ponderação de valores, interesses, etc., são claros incentivos a essas práticas, que de judicialização pouco têm, mas têm muito de ativismo. Nesse ponto, falha a doutrina ao não criticar adequadamente esses "incentivos legislativos ao ativismo".

Em uma palavra, quando um magistrado diz que julga "conforme sua consciência" ou julga "conforme o justo" ou "primeiro decide e depois vai encontrar um fundamento" ou ainda "julga conforme os clamores da sociedade", é porque está repetindo algo enraizado no imaginário jurídico.

Um comportamento que se naturaliza leva muitos anos para "desnaturalizar". Transforma-se em dogmática, eliminando o tempo e as coisas (cronofobia e factumfobia). O que ocorre é que não queremos admitir que ideologizamos - para usar uma palavra suave - a aplicação da lei no País. Isso é facilmente verificável no conjunto de decisões.

A "ideologia" de que falo está nas práticas puramente consequencialistas e/ou teleológicas. Basta examinarmos a jurisprudência de turmas, câmaras ou Tribunais como um todo: por vezes se apela à clareza da lei (até utilizando a velha metodologia de Savigny, que, é importante ressaltar, não tinha muita consideração pelo legislador ou pela lei), em outras, no mesmo dia, diz-se que a lei é apenas a ponta do iceberg, "essa lei é injusta", "os fatos sociais foram adiante da lei", "o contexto social fala mais alto" ou, ainda, simplesmente, lança-se mão de pseudoprincípios para justificar a primazia da escolha do juiz sobre uma regra jurídica votada pelo Parlamento.

Só que tudo isso é dito para cima e para baixo, isto é, os mesmos julgadores que apelam a uma pretensa literalidade lançam mão, em outros momentos, de um arcabouço de argumentos morais para corrigir a legislação. E, assim, a moral corrige o direito. ${ }^{5}$ Por exemplo, o mesmo Tribunal que considera claro um dispositivo do CPP no que se refere à oitiva de testemunhas, considera que mais de um ano e meio de prisão preventiva configura apenas um pequeno atraso, e isso justifica a manutenção da prisão cautelar.

De outro lado, não é difícil para um Tribunal sustentar que é possível usucapião em terras públicas, sob o argumento de que a União não comprovou que a área é importante para a estratégia nacional. Entretanto, o Tribunal não percebe que essa decisão, levada a ferro e fogo, em termos de coerência e integridade, pode colocar por terra o próprio dispositivo constitucional que trata de terras públicas. Onde está a "clareza" ou a "obscuridade" nesses casos e em outros milhares?

Por exemplo, é de se pensar em como conciliar esse enorme leque de decisões que, por vezes olhadas isoladamente, até nem parecem decisões ativistas. Entretanto, comparando com outras sobre matéria similar, somos obrigados a olhar com maior atenção. Recentemente um juiz federal absolveu um refugiado sírio por ter falsificado seu passaporte. A sentença não dá detalhes sobre algumas ques-

\footnotetext{
5 Aqui a importância do conceito de cooriginariedade entre moral e direito, conforme bem acentua Habermas. A moral da "razão sozinha" é muito frágil, diz o autor. Por isso, necessita de institucionalização no sistema jurídico. Isso quer dizer um alívio para o indivíduo (leia-se, para o caso, o julgador) que não precisa carregar o peso cognitivo da formação do juízo moral próprio. Caso tivesse que confiar somente em moral, jamais se poderia estar seguro sobretudo de que igualmente a outra parte agiria dessa forma. Essa incerteza motivacional é absorvida pela facticidade da imposição do direito. Direito é coercitivo. Moral, não. Nesse sentido, ver Habermas (2003).
} 
tões arroladas, como comprovação de que o refugiado não conseguirá trabalho ou se sua irmã mora em Londres, etc. (deve estar nos autos, mas não está na decisão). A absolvição ocorreu, com a aquiescência do Ministério Público Federal (MPF), sob a tese da inexigibilidade de outra conduta. Teleologicamente a decisão pode estar correta. Mas essa pode ser uma opinião moral sobre o caso. ${ }^{6}$

No caso, como responder a perguntas como Mas não havia mesmo outra conduta ao refugiado a seguir? Não havia outra conduta a se exigir de alguém que recebe o visto de refugiado? Ele tem de falsificar sua saída? Isso é conduta diversa? Em casos similares, essa decisão pode ser repetida? E se vale para refugiados, outras pessoas poderão falsificar passaportes? O problema está na pessoa do refugiado ou no tipo penal? O direito penal é do fato ou do autor? Na verdade, quando nos interessa, alegamos que o direito penal é do fato. Mas, por vezes, queremos que seja do autor, mesmo que esse mesmo argumento (moral), em outras circunstâncias, possa ser um tiro no pé.

Podemos concordar com o resultado, mas a fundamentação não convence. Veja-se: dias antes, o mesmo juiz condenou um estrangeiro por transportar quatro ovos de condor, ave considerada em extinção. A pena chegou a mais de um ano por ovo, por assim dizer. Sim, sei que é crime ambiental. A questão não é saber se o resultado foi correto. A questão é saber se ambas as decisões podem ser corretas, jurídica e constitucionalmente.

Ao mesmo tempo, o STJ concede liminar em reclamação dizendo que o ato de entregar automóvel a terceiro é um crime de perigo abstrato. Pior: a comunidade jurídica, impregnada da síndrome de Ettiene de la Bottié, ${ }^{7}$ não percebe que, com esse tipo de decisão em sede de reclamação, estabeleceu-se um sistema cassatório, por aqui, por intermédio de um instituto que não é recurso. A comunidade jurídica esquece que a reclamação surgiu para preservar a autoridade de decisões, só que acabou por se transformar — darwinianamente - em um instituto que vincula a jurisprudência. $\bigcirc$ que é um texto jurídico, afinal?

Poderia também falar das inúmeras decisões reconhecendo vários pais para o mesmo filho, avós em dobro, tornozeleira para pena de 13 anos, etc. Logo teremos o registro de tios, tias e padrinhos, tudo em nome dos pseudoprincípios da felicidade e da afetividade. Sim: o utente poderá alegar que é um direito fundamental ter o registro de uma madrinha determinada no seu registro de nascimento. Repito a pergunta: o que é um texto jurídico, afinal?

Daí a pergunta que deve ser respondida: o Direito, ao fim e ao cabo, é o que dele se diz por aí ou, melhor, ele é o que o juiz discricionariamente diz que ele é? Mas se isso é assim, se já se "naturalizou" essa concepção, porque continuamos a estudar ou escrever sobre o Direito? Não seria melhor deixar que "quem decide é quem sabe"?

Talvez o que falte é sabermos, mesmo, de verdade, se podemos ou não falsificar passaportes, se casa de prostituição é crime (e não somente nas pequenas cidades), se podemos ou não pegar ovos do condor, se podemos ou não entregar um carro (e se se exige ou não o perigo concreto, já que o terceiro

\footnotetext{
6 Por exemplo, é um bom exercício buscar compatibilizar essa apreciação sobre o fato (absolvição pelo crime de falsificação de passaporte), confrontando-a com decisão sobre refugiados como a recentemente proferida pelo TRF4 (FAMÍLIA..., 2016).

7 Faço referência a esse autor em razão de sua obra O Discurso da Servidão Voluntária e que, como o título já indica, ilustra muito bem a condição em que muitos juristas se encontram. Nesse sentido, ver De La Botié (1982).
} 
apenas responde concretamente, por mais paradoxal que isso possa parecer), quanto tempo alguém pode ficar preso preventivamente, o que é isso - a hipossuficiência que está claramente posta na CF, etc.

Enfim, bem que gostaríamos de saber antes, pelo menos, a partir de uma certa tradição, e não ficarmos apenas discutindo "o depois", isto é, ficar discutindo restos de sentido, verbetes, ementas, súmulas, etc., e sermos simplesmente "profetas do passado". E a doutrina se transformar em simples glosas do que os Tribunais-disseram-sobre-a-lei. O que será que queremos, mesmo? Etienne de la Botié nasceu em 1530 e morreu em 1563. Escreveu uma obra clássica: O Discurso da Servidão Voluntária. Parece ser uma obra escrita para a comunidade jurídica brasileira.

\section{A necessidade de uma resposta constitucionalmente adequada em direito: afinal, há sempre direitos fundamentais em jogo}

Os cidadãos, ao procurarem o Judiciário, acreditam que suas causas serão apreciadas e julgadas à luz do direito previamente estabelecido. Ou seja, não é um direito criado ex post facto, mas aquele que tem raízes na história institucional de sua comunidade. Não estamos a dizer que (pré) existe um direito já pronto para ser aplicado, é que existe uma tradição, uma narrativa que precisa ser reconstruída e que essa tarefa possui limites e parâmetros.

Nesse sentido, entendo que há um direito fundamental de obter uma resposta adequada à Constituição, que não é a única e nem a melhor. Cada juiz tem suas convicções pessoais e sua ideologia própria, mas isso não significa que a decisão possa refletir esse subjetivismo. $\bigcirc$ juiz precisa usar uma fundamentação que demonstre que a sentença ocorreu por argumentos de princípio, e não de política, de moral ou outro qualquer.

A institucionalização da moral no direito, a partir do direito gerado democraticamente (Constituições compromissório-sociais), mostra a especificidade do Estado Democrático de Direito. O direito incorporou um conteúdo moral, passando a ter um caráter de transformação da sociedade. Esse ideal de "vida boa" deve ser compreendido como dirigido e pertencente a toda a sociedade (esse é o sentido da moral), sendo a Constituição o modo para alcançá-lo.

Com desideratos semelhantes, em Habermas o direito - a Constituição - garante abertura para que a justiça social venha a ser construída ao longo do tempo - daí a ênfase em uma democracia procedimental; na hermenêutica - na leitura feita no espaço dessas reflexões - a aplicação da Constituição representa a concretização do conteúdo substancial e dirigente do texto; a hermenêutica não prescinde do procedimento, mas aposta na realização dos direitos substantivos, que têm caráter cogente, decorrendo, assim, uma maior valorização da jurisdição constitucional.

Afastando-se do relativismo, a Crítica Hermenêutica do Direito (CHD) entende ser possível dizer, sim, que uma interpretação é correta, e a outra é incorreta (ou adequada ou inadequada em relação à Constituição). Movemo-nos no mundo exatamente porque podemos fazer afirmações dessa ordem. E disso nem nos damos conta.

Ou seja, na compreensão, os conceitos interpretativos não resultam temáticos enquanto tais, como bem lembra Gadamer; ao contrário, determinam-se pelo fato de que desaparecem atrás 
daquilo que eles fizeram falar/aparecer na/e pela interpretação. Aquilo que as teorias da argumentação ou qualquer outra concepção teorético-filosófica (ainda) chamam de "raciocínio subsuntivo" ou "raciocínio dedutivo" nada mais é do que esse "paradoxo hermenêutico", que ocorre exatamente porque a compreensão é um existencial (ou seja, por ele eu não me pergunto porque compreendi, pela simples razão de que já compreendi, o que faz com que minha pergunta sempre chegue tarde).

Ao contrário do que se diz, não interpretamos para, depois, compreender. Na verdade, compreendemos para interpretar, sendo a interpretação a explicitação do compreendido, para usar as palavras de Gadamer. Essa explicitação não prescinde de uma estruturação no plano argumentativo (é o que se pode denominar de "como apofântico"). A explicitação da resposta de cada caso deverá estar sustentada em consistente justificação, contendo a reconstrução do direito, doutrinária e jurisprudencialmente, confrontando tradições, enfim, trazendo a lume a fundamentação jurídica que, ao fim e ao cabo, legitimará a decisão no plano do que se entende por responsabilidade política do intérprete no paradigma do Estado Democrático de Direito.

\section{Considerações finais}

Diante do exposto, parece indispensável entre as discussões sobre os desafios da concretização dos direitos fundamentais no século XX estar presente uma reflexão a respeito da função e dos limites da atividade jurisdicional, uma vez que estes se encontrarão em juízo, e nesse momento há que se ter uma decisão jurídica devidamente fundamentada. Respostas equivocadas fragilizam não apenas a segurança jurídica, mas também a democracia e os direitos fundamentais assegurados pela Constituição. Antes de tudo, há um direito fundamental a uma resposta adequada à Constituição.

Por isso, na realidade brasileira de colonização do mundo da vida pelo Judiciário é importante entender a diferença entre ativismo e judicialização da política. Para além de uma criteriologia quantitativa, o primeiro se caracteriza por uma atuação judicial que extrapola os limites jurídicos (Constituição, Princípios Jurídicos, Leis, Jurisprudência, etc.) e/ou invade a competência dos demais Poderes; já a segunda é uma contingência histórica que ocorre de tempos em tempos, sobretudo em países periféricos de modernidade tardia que possuem uma constituição analítica como o Brasil.

Diante desse maior espectro de atuação do Judiciário, a questão que se coloca é como as decisões são construídas. Por isso, há que se ter cautela com recepções teóricas (equivocadas) que não se coadunam com a realidade brasileira ou que "escondem" posturas subjetivistas, casos da Jurisprudência dos Valores ou da Ponderação Alexyana, ou sua versão tupiniquim. Nesta quadra da história temos que dar um salto da subjetividade para a intersubjetividade, dos donos dos sentidos para os sentidos que ocorrem em um a priori compartilhado. Desse modo, em vez da discricionariedade, das escolhas, teremos decisões que se acomodam em uma construção democrática do direito.

Assim, partindo do dever fundamental de justificar/motivar as decisões, chegamos ao direito fundamental à obtenção de respostas corretas/adequadas à Constituição. Mais do que isso: a concretização dos direitos fundamentais requer a obtenção de respostas adequadas à Constitui- 
ção. Trata-se de um direito (humano) fundamental do cidadão, ou seja, o cidadão tem o direito a uma accountabillity hermenêutica. Há uma ligação umbilical entre esse dever fundamental e esse direito fundamental. A complementaridade entre ambos representa uma blindagem contra interpretações deslegitimadoras e despistadoras do conteúdo que sustenta o domínio normativo dos textos constitucionais.

\section{Referências}

DE LA BOTIÉ, Etienne. O Discurso da Servidão Voluntária. São Paulo: Brasiliense, 1982.

FAMÍLIA não consegue visto de refugiado por ainda não estar no Brasil. Consultor Jurídico, 04 jan. 2016. Disponível em: <http://www.conjur.com.br/2016-jan-04/familia-nao-visto-refugiado-nao-estar-brasil>. Acesso em: 12 jun. 2016.

HABERMAS, Jürgen. Direito e Democracia: entre facticidade e validade. Rio de Janeiro: Tempo Brasileiro, 2003. v. 1.

OLIVEIRA, Marcelo Andrade Cattoni de. Devido Processo Legislativo: uma justificação democrática do controle jurisdicional de constitucionalidade das leis e do processo legislativo. Belo Horizonte: Fórum, 2015.

RIO DE JANEIRO (Estado). Agravo de Instrumento n. 0033615 - 54.2015.8.19.0000. Agravante: Município de Campos dos Goytacazes. Agravado: Ministério Público do Estado do Rio de Janeiro. Relator: Desesembargador Alexandre Freitas Câmara. Julgamento em 09 dez. 2015.

RODRIGUES, Fernando. 'Inércia do Congresso traz riscos para a democracia', diz Barroso. Folha de São Paulo, dez. 2013. Disponível em: <http://www1.folha.uol.com.br/poder/poderepolitica/2013/12/1388727-entrevista-com-luis-roberto-barroso.shtml>. Acesso em: 12 jun. 2016.

STRECK, Lenio Luiz. Hermenêutica Jurídica e $(m)$ Crise: uma exploração hermenêutica da construção do Direito. 11. ed. Porto Alegre: Livraria do Advogado, 2013.

STRECK, Lenio Luiz. Jurisdição Constitucional e Decisão Jurídica. 4. ed. São Paulo: Revista dos Tribunais, 2014a.

STRECK, Lenio Luiz; OLIVEIRA, Rafael Tomaz de; BARRETTO, Vicente de Paulo. Ulisses e o canto das sereias: sobre ativismos judiciais e os perigos da instauração de um terceiro turno da constituinte. RECHTD. Revista de Estudos Constitucionais, Hermenêutica e Teoria do Direito, v. 1, 2009.

STRECK, Lenio Luiz. O que é isto - decido conforme minha consciência? 5. ed. Porto Alegre: Livraria do Advogado, 2015.

STRECK, Lenio Luiz. O que é isto, o ativismo judicial, em números? Disponível em: <http://www. conjur.com.br/2013-out-26/observatorio-constitucional-isto-ativismo-judicial-numeros $>$. Acesso em: 14 jun. 2016.

STRECK, Lenio Luiz. Verdade e Consenso. 5. ed. rev., atual. e ampl. São Paulo: Saraiva, 2014b. 
VIANNA, Luiz Werneck. Não há limites para a patológica judicialização da política. Disponível em: $<$ http://www.conjur.com.br/2016-jan-03/luiz-werneck-vianna-nao-limites-judicializacao-politica>. Acesso em: 14 jun. 2016.

Data da submissão: 19 de setembro de 2016 Avaliado em: 24 de outubro de 2016 (AVALIADOR A) Avaliado em: 24 de outubro de 2016 (AVALIADOR B) Aceito em: 03 de novembro de 2016 